\title{
Certification requirements for tram noise measurements in terms of today's expectations in cities
}

\author{
M. Motyl, T. Nowakowski, B. Czechyra \& B. Firlik \\ Department of Rail Vehicles, Poznan University of Technology, Poland
}

\begin{abstract}
Technical requirements for the tram certification process are different between particular EU countries. Uniformity for this procedure is not required in view of the infrastructure of closed cities, hence the Technical Specifications for Interoperability (TSI) are not valid. The certification process includes a lot of evaluation aspects for tram interaction in highly urbanized cities. One of them is noise, the level of which depends on the quality of interaction between vehicles and the infrastructure. In homologation tests, stationary, pass-by and signaling noise measurements are included. However, not all of these requirements can always be implemented in cities due to the course of an operated tram network. One of the requirements is the distance from the track axis to the measurement position described as $7.5 \mathrm{~m}$. This requirement is difficult to reflect for a real tram infrastructure, especially in city centers and vintage city areas. For this reason, we can only partially fulfil all standard requirements. This leads to problems with the interpretation of results and impedes final verification of vehicle condition in terms of the fulfilment of operator's requirements contained in tender specifications and technical standards. Presented problems entail the need to evaluate existing technical requirements in terms of their feasibility in cities. The paper presents a comprehensive analysis of the certification requirements for noise level measurements with regard to the Polish city selected. The authors analyzed a tram infrastructure and its environment in terms of the ability to fulfil existing standards conditions for homologation tests.
\end{abstract}

Keywords: tram, noise measurement, certification, ISO 3095. 


\section{Introduction}

City rail transport is becoming more and more an essential element of a transport system in a contemporary urban area. It is first of all thanks to its functionality connected with the large capacity of the vehicles and the possibility to ensure the high mobility of the citizens. Despite the lack of direct emission of the compounds harmful to the environment, the trams generate environmental pollution in the form of noise and vibration. That is why the requirements we have from new rail transportation means for cities concern many technical aspects, i.e. the security and reliability of a vehicle but also ensuring the appropriate vibro-acoustic comfort for the future passenger - comfort of vehicle ride - and to the travellers on the nearby tram lines as well because it constitutes the quality of life in the city. The vibro-acoustic effects generated by the trams are inherent. Their levels depend strictly on the interaction of the tram with the railway. That's why it is important to check the interaction between the new-build or modernized vehicle with the existing infrastructure.

There is a fundamental difference in the process of permittance for driving a tram and the other rail vehicles. The trams are subjected to the requirements of the Technical Interoperation Specifications (TSI) and the Operation Directive 2008/57/WE as well, which are applied in all member countries of the EU. Certification of approval is carried out in different ways in each country of the EU. There are not so many technical standards for the trams which allows for bigger freedom in their design.

\section{Legal and technical requirements}

The legal basis for the certification of the approval process concerning a tram vehicle is the Law Traffic Regulation [1]. On the basis of it we have elaborated appropriate executive acts. In general requirements of the order [2] we have reference to the vibro-acoustic activity of a tram; we have listed the limited level values of the noise corrected by the A characteristic outside the vehicle at times of driving and during stopover. In the first case, this value is $80 \mathrm{~dB}$ and it concerns driving with a constant velocity of $50 \mathrm{~km} / \mathrm{h}$ on the chosen breakstone railway with reinforced concrete sleepers while the limited noise value at times of stopover is $64 \mathrm{~dB}$. For these two cases, the measurement points were specified at a height of $1.2 \mathrm{~m} \pm 0.2 \mathrm{~m}$ above the track head with a difference in the distances: for driving measurement $-7.5 \mathrm{~m}$ from rail axis, and during the stopover $-6 \mathrm{~m}$ from the side of the vehicle. It is required by the certification of approval procedures concerning the tram types that only the authorized units can carry out the tests [3].

The Polish Law Acts here presented do not comprise the full research methodology for determining the noise level generated by a tram, nor do we have a specific analysis method of the obtained signals. In this purpose the requirements of the standard ISO 3095 [4] are commonly used and they comprise all indispensable recommendations and they permit us to repeat the measurements. Thanks to this, it is possible to compare between them the measurement results obtained. One of the essential recommendations is to retain the exact measurement 
conditions. The research area should be flat and free from big reflecting objects within a $22.5 \mathrm{~m}$ radius from the microphones. The measurement point concurs with Polish Law (Fig. 1). Moreover, it is essential to keep the same atmospheric conditions - particularly concerning wind speed and lack of precipitations.

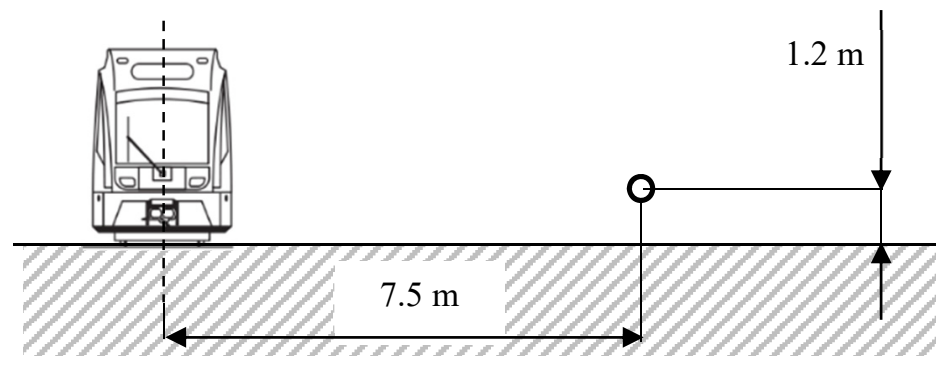

Figure 1: Main microphone positions for measurements on vehicles with constant speed.

The standard recommendations do not comprise the limit values for the parameters measured. These limit values are taken from the law regulations of a particular country; it is a required criterion to allow the vehicle to operate. These values could be freely tightened in the Specifications of Essential Order Conditions delivered by the orderer together with an order for new or modernized vehicles. That's why the city transportation enterprises take into consideration the noise level generated by the vehicle which is declared by the producer. If the level noise is lower, the scoring for the offer is higher. The noise level generated by the tram and declared by the producer is finally verified during the process to allow the vehicle to operate. The acoustic measurements should be carried out in accordance with the law requirements of a given country and the standard ISO 3095. Unfortunately, fulfilling the requirements, especially to keep the appropriate distances from the objects which could disrupt the measurements, is difficult because the tram network is often situated in an area with buildings of historical value and in the city center. However, to make the measurements when the conditions differ from the standard creates problems with the interpretation of measurement results and it complicates the verification of the transportation means. At the current time, the large activities of local governments, having as a purpose to change the tram fleet, are supported by the EU. The financial means destined for this purpose in the current perspective enables us to make numerous transportation investigations in Poland. Definitive verification of a vehicle will have place in the railway infrastructures of cities. The verification conditions are therefore crucial for the certification of approval and they should be carried out correctly. Therefore, the analysis of the possibility to carry out the process of the certification of approval concerning the trams - taking into consideration the fulfilling the standard requirements for the noise measurement in Poznan City (PL) as a sample - were carried out. 


\section{Analysis of the tram network}

The tram network in Poznan City has $190 \mathrm{~km}$ of lines and we can single out more than 10 types of lines. Within this network we have 20 lines by day, 1 line by night and 1 tourist line. We have in use altogether 226 tram sets where we have 8 tram types.

The tram network presented was examined, taking into consideration the possibility of fulfilling the conditions for noise measurement during the process of the tram certification of approval. On the basis of the standard ISO 3095 requirements and the law acts being in effect in Poland, the criterion of searching for the research area $\mathrm{C}$, where the measurements could be carried out, were determined in eqns (1) and (2).

$$
\begin{gathered}
\mathrm{C}=\{\mathrm{U} \cap \mathrm{V} \cap \mathrm{M}\} \\
\mathrm{U}, \mathrm{V}, \mathrm{M} \in \mathrm{T}
\end{gathered}
$$

where:

$\mathrm{C}$ - the acoustic measurements area,

$\mathrm{U}$ - the line segment with the best technical condition,

$\mathrm{V}$ - the line segment enabling the ride with a speed of $50 \mathrm{~km} / \mathrm{h}$,

$\mathrm{M}$ - fulfilling the requirements for the area around the microphones,

$\mathrm{T}$ - the sectioned breakstone lines with reinforced concrete sleepers.

The final measurement area was chosen on the basis of the technical documentation and the data obtained from the infrastructure administration. First of all, from the existing infrastructure, rubble bed lines with reinforced concrete sleepers were chosen, especially those lines which have the best technical condition. Such criterion enables a good quality interaction between the vehicle and the railway in order to minimize the noise bound up with the line irregularity what directly gives us an increased noise level [5]. After that, the line segments enabling the ride with the speed of $50 \mathrm{~km} / \mathrm{h}$ were selected. These segments had to be free from obstacles, such as frogs and traffic lights. Finally, the chosen segments were checked, taking into account the possibility of the standard for placing the microphone. Figure 2 shows the destination research area for the acoustic measurements where the required criterion is fulfilled.

The chosen measurement area constitutes a 2-track segment about $200 \mathrm{~m}$ long. It is between Termy station and Krancowa station and is situated at the side of the roadway located $14.5 \mathrm{~m}$ from the track. The closest buildings are situated within about a $98.5 \mathrm{~m}$ radius while the tree strip - within about a 58 m radius. 


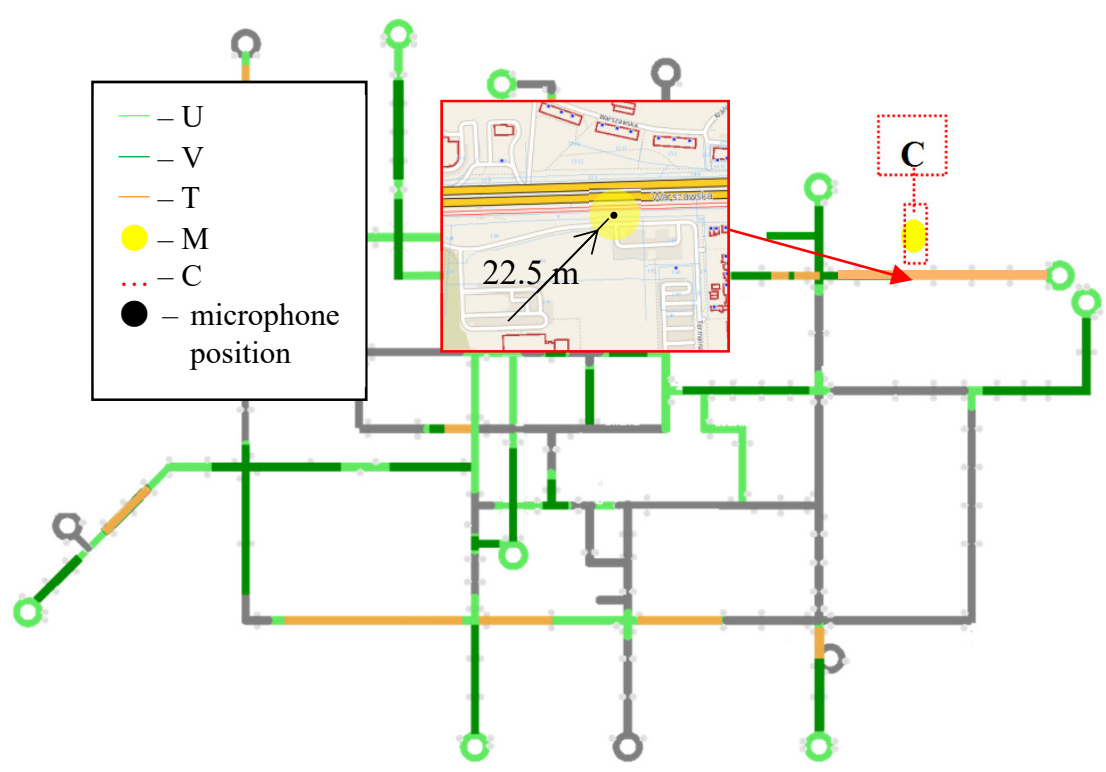

Figure 2: Scheme of the tram network in Poznan City with the selected measurement section of track [6].

\section{Summary}

The analysis carried out proves how the procedure of selecting the research area for the tram acoustic measurements is complicated. Only one area - from the whole analysed track infrastructure - was chosen which enabled us to carry out the standard acoustic measurements connected with the certification of approval process for the new or modernized trams. As the track was situated at the side of the roadway we were provided with a comfortable position for taking the measurements. The proximity of a roadway creates the necessity of taking the measurements by moving close to it. The correct time is therefore at night as the acoustic background is lower and the consequences of the road closing are smaller.

The results of the analysis performed could be a valuable contribution for using the recommended track segment as a permanent verification segment for the tram homologation process in Poznan City. Furthermore, this track segment could be used for the analysis of the influence of new tram design solutions in reference to the acoustic phenomena emitted. Therefore, the selected track segment should have the maintenance priority for keeping them in highest technical condition.

As the ISO 3095 standard is used only for tram comparison measurements it is necessary to put into the process of homologation the quality evaluation of the influence of a new tram to the nearest environment of the tram lines. 


\section{Acknowledgements}

All presented work is realized within the framework of the Research Project "Innovative Urban Tram" (WND-DEM-1-281/00), within the Demonstrator+ Programme of the National Centre for Research and Development, co-financed by the European Regional Development Fund under the Operational Programme Innovative Economy.

\section{References}

[1] The Polish Act from 20 June 1997 - Law of Road Traffic (Ustawa z dnia 20 czerwca 1997 r. - Prawo o ruchu drogowym. Dz.U. 1997 r., Nr 98, poz. 60)

[2] Regulation of the Minister of Infrastructure from 2 March 2011. On the technical conditions of trams and trolley buses, and the scope of necessary equipment (Rozporządzenie Ministra Infrastruktury z dnia 2 marca 2011 r. w sprawie warunków technicznych tramwajów i trolejbusów oraz zakresu ich niezbędnego wyposażenia. Dz.U. 2011, Nr 65, poz. 344)

[3] Regulation of the Minister of Transport, Construction and Maritime Economy from 28 May 2013. On type approval of trams and trolleybuses (Rozporządzenie Ministra Transportu, Budownictwa i Gospodarki Morskiej z dnia 28 maja 2013 r. w sprawie homologacji typu tramwajów i trolejbusów. Dz.U. 2013, poz. 688)

[4] ISO 3095:2013, Acoustics - Railway applications - Measurement of noise emitted by railbound vehicles

[5] Thompson D. Railway noise and vibration: mechanism, modeling and means of control. 1st ed. UK: Elsevier Science \& Technology; 2009

[6] MPK Poznań - company technical materials 